\title{
Role of community health service programs in navigating the medical ethical slippery slope-a 10-year retrospective study among medical students from southern China
}

Guanhua Fan', Zhenhua Lin², Yizhen Luo ${ }^{3}$, Maohuai Chen ${ }^{1}$ and Liping Li $i^{*}$

\begin{abstract}
Background: For promoting autonomous learning motivation, the learning effect of community-oriented service is beneficial, because through community participation and service, students can transfer their implicit cognition of ethics into explicit cognition, leading to the cultivation of a sympathetic partnership between the community and medical students. Despite the proven benefits of medical students' community health service (CHS) in Western countries, CHS programs designed for medical students are not well established in mainland China, and their effects on medical students' ethical cognition are largely unknown. This study evaluated the effects of CHS programs on the ethical cognition of medical students.
\end{abstract}

Methods: A cross-sectional study was conducted on third- and fourth-year medical students and graduates working at Shantou University Medical College by using a self-administered anonymous questionnaire. Through interviews, we applied a thematic approach to analyze the responses of the participating students. The questionnaire adopted in this study was revised based on a review of the literature on medical ethics in medical students and on the CHS environment in China. The reviewed questionnaires included an evaluation questionnaire on cultivating medical ethics in a CHS context, and questionnaires used to explore the cultivation and transformation of medical ethics in medical students during the preclinical period.

Results: A total of 361 (54.4\%) undergraduate medical students and 302 (45.6\%) graduates participated in this survey. Significant differences were observed in self-evaluation of the cognitive development of ethics between those who had participated in CHS programs 1-5 times and those who had participated $>6$ times. The successful identification of accepting money from the patients under the table as unethical behavior significantly differed $(p=.031)$ among the graduates but not $(p=.567)$ among the undergraduate students. The participants expressed the positive impact of CHS programs on their self-development.

Conclusion: CHS programs can be widely applied in medical education in China. This educational strategy, which supports medical professionalism and incorporates humanitarian behavior as a complement to learning, should be encouraged and promoted nationally.

Keywords: Community medicine, Community health service, Community health education, Health promotion in rural areas, Medical student, Cognitive level, Medical ethics

\footnotetext{
* Correspondence: Ipli@stu.edu.cn

'Shantou University Medical College, 22 Xin Ling Road, Shantou 515041,

China

Full list of author information is available at the end of the article
}

(c) The Author(s). 2019 Open Access This article is distributed under the terms of the Creative Commons Attribution 4.0 International License (http://creativecommons.org/licenses/by/4.0/), which permits unrestricted use, distribution, and reproduction in any medium, provided you give appropriate credit to the original author(s) and the source, provide a link to the Creative Commons license, and indicate if changes were made. The Creative Commons Public Domain Dedication waiver (http://creativecommons.org/publicdomain/zero/1.0/) applies to the data made available in this article, unless otherwise stated. 


\section{Background}

Chinese medical education and practice have long ignored the cultivation of professionalism in medical students. An article entitled "Lessons from the EastChina's rapidly evolving health care system," [1] published in the New England Journal of Medicine in in April 2015, states that the cultivation of Chinese doctors' professionalism, which concerns physicians, patients, hospitals, and medical colleges, has been an important part of the Chinese medicine revolution. However, as a solid foundation of the modern health system, the function of professionalism has not been paid sufficient attention. The lack of general professionalism has made the Chinese medical environment complicated and has made it difficult to cultivate leaders and trustworthy medical staff. The findings of this study indicate that the usefulness of a community health service (CHS) lies in whether medical students can apply what they have learned in the classroom to their practices within the CHS. Moreover, through reflection, students' civic awareness can be improved [2]; thus, reflection has become an important component of medical education worldwide and is being applied in the teaching processes of many colleges and universities. The use of CHS programs in academic study can help students in more clearly understanding the needs of patients and in more effectively solving practical problems [3-5].

CHS activities improve students' awareness regarding the importance of the long-term management of chronic diseases. In China, severe chronic diseases, including cancer, have become the leading cause of mortality [6]. Residence in a rural area, a low yearly family income, and a low educational level were reported as behavioral risk factors related to severe chronic diseases [7]. In China, more than $60 \%$ of the population lives in rural areas, and the health care and public health facilities are still relatively underdeveloped [8, 9]. Long-term mechanisms, including cooperation between the government and media, should therefore be established to promote countrywide CHS programs for the benefit of medical students and economically disadvantaged populations in mainland China [10].

Social cognitive theory (SCT) assumes that the learning behavior of humans mostly occurs in the social environment. In a dynamic society, personal factors, the environment, and human behaviors continually interact [11], indicating that personal behaviors are the result of reciprocal determinism between humans' cognition and environment. In other words, the mutual effect of the environment, behaviors, and personal factors, such as cognition, is persistent [12], and humans learn social behaviors and conduct through observing other people [13]. SCT explains the reciprocal action of CHS on medical students' behaviors, conduct, and environment.
However, the identification of a method for assessing the efficiency of community medical service is challenging [14]. If we intend to particularly emphasize the participants' learning efficiency, quantitative research methods can be used. To date, the most commonly used method for evaluating the efficiency of CHS is self-evaluation reports [15].

Community medical activities make useful contributions to medical education, particularly by exposing medical students to CHS and providing first-hand experience of common environmental and living health concerns [16-19]. This promotes the development of care for others and facilitates essential abilities, such as communication, leadership, teamwork, understanding of health, and development of cognitive-emotional dimensions [20-22].

Holistic medicine and medical students' professionalism require the provision of respect, care, and support through empathizing with and understanding those in need, which is an essential ability for current medical students [23]. However, the deficient cultivation of professionalism is the greatest challenge in Chinese medical education [24]. In summary, teaching students to first be an ethical person and then an ethical professional should be a goal of Chinese medical education. In mainland China, CHS programs are still in the exploratory stages, especially in terms of their application in medical education. Shantou University Medical College (SUMC) has incorporated $\mathrm{CHS}$ into medical education in mainland China since 2004. China has an immense agricultural population with considerable social expenditure and income inequality, especially between the urban and rural areas [25]. Hence, CHS programs are provided for the low-income sectors of society, particularly in economically underdeveloped areas. These CHS programs are funded by the Li Ka Shing Foundation and supported collectively through regular clinics, home-based service units, and medical art performers [26]. The learning objectives of the service programs of SUMC include community health assessment, risk behavior change, assistance with personal health services (e.g., for patients with advanced cancer and their families), advocacy and policy change, environmental interventions, medical training for rural communities, partnership-building for children and older adults in the families of cancer patients, and program evaluation $[27,28]$. The learning objectives are interwoven across the undergraduate and graduate students' curricula as they gain skills in creating, delivering, and evaluating evidence-based public health approaches at the community level [29] (Table 1).

To cultivate medical talent, SUMC offers a 8-year course, which consists of 5 years of preclinical courses and 3 years of clinical rotations. The main participants in CHS programs in this study were third- and fourthyear medical students. These programs were held on 
Table 1 Main platforms for CHS in SUMC

\begin{tabular}{|c|c|}
\hline Platform & Content and outcome offers of $\mathrm{CHS}$ activities \\
\hline $\begin{array}{l}\text { National hospice } \\
\text { plans of Li Ka } \\
\text { Shing } \\
\text { Foundation } \\
\text { (founded in } \\
\text { 1998) }\end{array}$ & $\begin{array}{l}\text { Poor patients with advanced tumors are provided } \\
\text { with physical, mental, social, and spiritual types of } \\
\text { analgesic treatment and psychological support } \\
\text { through home-based services. The quality of life sta- } \\
\text { tus of patients with advanced cancer is considered } \\
\text { the main outcome measure for palliative care ser- } \\
\text { vices [30, 31]. CHS in hospices, as a special phase of } \\
\text { palliative care, provides interprofessional and multi- } \\
\text { dimensional care for patients with advanced cancer } \\
\text { and their families [32-34]. }\end{array}$ \\
\hline $\begin{array}{l}\text { National health- } \\
\text { related antipov- } \\
\text { erty project of Li } \\
\text { Ka Shing Foun- } \\
\text { dation (founded } \\
\text { in 1998) }\end{array}$ & $\begin{array}{l}\text { The travel of medical students to poor, rural areas, } \\
\text { including the provinces of Fujian, Jiangxi, } \\
\text { Guangdong, Guangxi, Yunnan, and Tibet, is } \\
\text { organized to execute health-related antipoverty ac- } \\
\text { tivities. Medical ethics education and the training of } \\
\text { a large number of local medical personnel are } \\
\text { promoted. }\end{array}$ \\
\hline
\end{tabular}

weekends to avoid conflict with the students' regular school learning.

Although participation was voluntary and not awarded with class-hour credits, most of the students were willing to participate in their spare time. All participants were trained by clinical teachers for acquiring knowledge on chronic diseases and the local cultural and social characteristics. In the mornings, volunteer experts provided clinical service, and the students joined them during patient encounters, if necessary. The students provided patients with education and physical examinations, including free health screening for high blood pressure, obesity evaluation (body mass index measurement), random blood glucose tests, and eye examinations, at their own discretion. During the service activities, the students distributed self-designed leaflets describing common diseases to the local villagers. During home-based service in the afternoons, the students, accompanied by experts, interacted more closely with the patients' families to obtain first-hand experience of their common environmental and living health concerns. Each semester, the students sent performers with distinct talents and resources to the countryside. In addition to traditional performances such as singing, dancing, instrumental music, comedy, and magic shows, they offered humorous performances regarding first aid techniques, including demonstrations for fire emergencies, electric shock treatment, and cardiopulmonary resuscitation. After the programs, feedback and comments were obtained through e-mail, telephone, and postal mail.

Services and learning complement each other. These activities offer medical students the opportunity to provide medical service to rural communities, many of which have limited access to basic health care. CHS is an educational laboratory for the application of knowledge [33, 34]. Through these programs, students' social responsibility and awareness are improved, and poor, rural populations can acquire a high quality of medical services. Although CHS programs have been integrated into medical education in mainland China for 10 years, the effects of CHS programs on the cognition of medical ethics had not been evaluated. Therefore, the emphasis of this study was on cognition, or students' thoughts regarding medical ethics before and after they participated in CHS programs, rather than on knowledge development [35]. The specific objective of this study was to determine the effects of CHS programs so that the quality of undergraduate medical education and the concept of CHS in China can be improved.

The perceptions of medical students toward medical ethics have been studied previously, with attributes such as altruism, autonomy, caring, and compassion often listed by students as the most important with regard to medical ethics. However, others are often emphasized, such as leadership, excellence, creativity, motivation, values, aspirations, self-confidence, and initiative [36, 37]. Medical ethics cognition is a concept with high cultural sensitivity that develops with time and changes according to social values. Consequently, the differences between Western and East Asian cultures can be stark. Based on the medical situation in mainland China and due to cultural differences, medical ethics cognition should be explored and developed while accounting for local cultural characteristics. Thus, in addition to CHSs, Chinese medical students' understanding and rationale regarding medical ethics should be explored, which is a topic on which no systematic research has been conducted previously.

\section{Methods}

Data collection

This section has been divided into Data Collection and Data Processing and Results subsections to illustrate our research process.

The questionnaire adopted in this study was revised based on a review of the literature on medical ethics among medical students and the CHS environment in China. These included a questionnaire used to evaluate the cultivation of medical ethics in a CHS context [38], and questionnaires used to explore the cultivation and transformation of medical ethics in medical students during the preclinical period [39-44]. After the questionnaire for this study was compiled, experts were invited to examine its content validity, and the questionnaire was pretested based on the experts' revisions. After the questionnaire was finalized, it was used to conduct on-site surveys of the respondents.

In addition to benefitting the community, CHS promotes the development of students' cognitive ability, morality levels, self-awareness, and self-confidence [45]. On the basis of previous studies, this retrospective crosssectional descriptive study utilized a mixture of qualitative 
and quantitative methods. We mainly focused on the effects of CHS programs on the cognition of medical ethics and therefore designed a self-administered anonymous questionnaire containing the following items:

(a) demographic characteristics,

(b) self-evaluation of ethical sensitivity development, and

(c) self-reports of ethical behavior.

All investigators were given uniform training. The questionnaires were hand-delivered to all participating medical students from the school and physicians who had graduated and worked at the hospital.

Comparisons of categorical data were performed using the Pearson chi-square test. The Statistical Package for Social Sciences (IBM SPSS Statistics 19.0) was used for data analysis, and the level of statistical significance was set at the conventional $p<.05$.

The questionnaire formed the basis of the content for the interview, which consisted of a series of open-ended questions regarding the impact of CHS on the cognitive development of the participants. The interview was conducted by two trained interviewers, and all participants provided verbal informed consent $[46,47]$. We audiorecorded all interviews, and all recordings were transcribed into text by two authors. The interviews were transcribed verbatim and thematically analyzed using NVIVO 10 software.

\section{Data processing and results}

This study enrolled graduate and undergraduate medical students who participated in CHS from January 2008 to July 2017, and they were invited to complete the questionnaire and receive brief interviews. A total of 876 individuals were invited to participate. Of these, 663 completed the questionnaire and attended the interviews, for a response rate of $75.6 \%$. Out of the 663 respondents, 361 (54.4\%) were undergraduate students and $302(45.6 \%)$ graduates. Table 2 shows the demographic characteristics of the study population; no significant differences were observed between the groups. A total of $48.5 \%$ (175/361) of the students and $68.2 \%(206 / 302)$ of the graduates had participated in CHS programs (Fig. 1).

In the graduate and undergraduate student groups, significant differences were observed in the selfevaluation of ethical sensitivity development between those who had participated in CHS programs 1-5 times and those who had participated more than 6 times (Table 2) (Fig. 2).

"Red envelope" indicates the receipt of money in addition to the normal treatment fee by physicians; this practice is unethical. Self-reports regarding the willingness to receive a red envelope significantly differed $(p=.031)$ among the graduates (Table 3$)$ but not $(p=.567)$ among the students (Figs. 3 and 4).

In addition, the researchers conducted a qualitative content analysis of the impact of CHS programs held in senior care facilities and in rural communities on the students' cognition of medical ethics. Interviews were conducted for those $(n=36)$ who participated in the CHS programs. In the study process, qualitative interview transcripts were formatted and imported into NVIVO 10 software for data management, coding, and analysis and were then coded by the qualitative team (Figs. 5 and 6 , Table 4 ).

The participants' perspectives regarding cognitive development through CHS programs are summarized in Table 5 . The views of the participants were generally very positive, as demonstrated in the following narratives:

Learned to transpose thinking and better understand and sympathize with the patients.

Enhanced our sense of responsibility and motivated us to study hard.

Enhanced our awareness of other people who need our help in society, especially those who are suffering from chronic diseases.

Motivated me to call on more people for participating in volunteer service to help more people.

Table 2 Characteristics of the study population

\begin{tabular}{|c|c|c|c|c|c|c|}
\hline & \multicolumn{3}{|c|}{ Undergraduate Students $(n=361)$} & \multicolumn{3}{|c|}{ Graduates $(n=302)$} \\
\hline & participant & non participant & $p$ & participant & non participant & $p$ \\
\hline & $n=175$ & $n=186$ & & $n=206$ & $n=96$ & \\
\hline \multicolumn{7}{|l|}{ Gender } \\
\hline Male & $103(58.9 \%)$ & $124(66.7 \%)$ & 0.125 & 131 63.6\%) & $59(61.5 \%)$ & 0.721 \\
\hline Female & $72(41.1 \%)$ & $62(33.3 \%)$ & & 75 36.4\%) & $37(38.5 \%)$ & \\
\hline \multicolumn{7}{|c|}{$\begin{array}{l}\text { Participating } \\
\text { frequency }\end{array}$} \\
\hline $1-5$ & $83(47.4 \%)$ & & & $11656.3 \%)$ & & \\
\hline$\geq 6$ & $92(52.6 \%)$ & & & $9043.7 \%)$ & & \\
\hline
\end{tabular}

"Participants" were those who participated in the CHS programs. "Nonparticipants" were those who had not participated in the CHS programs 


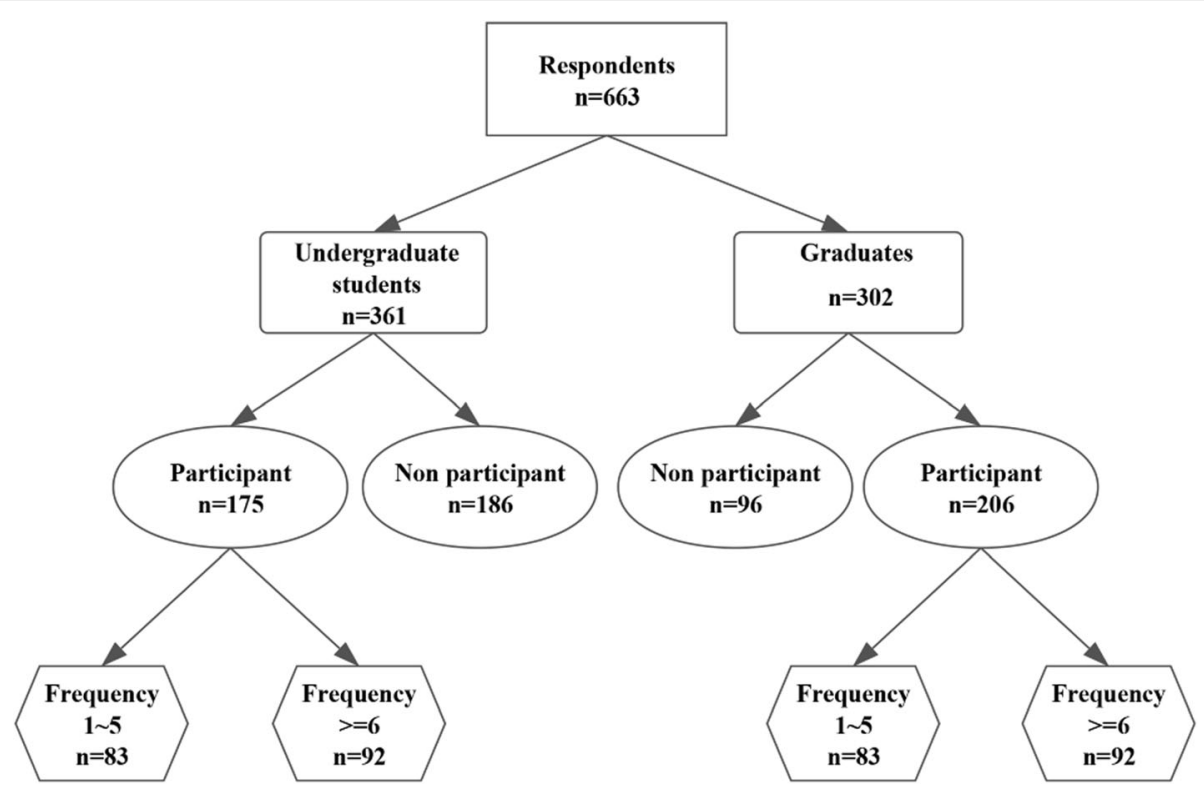

Fig. 1 Illustration of the data collection process

Accordingly, the following conclusions can be drawn: CHS activities can effectively increase students' participation in social services. The participants expressed willingness to care for disadvantaged groups, thus promoting continued service. The single CHS programs are adapted to undergraduate students. In addition to personal life inspiration, the participants also acknowledged the benefits of the joy of service, promotion of selfvalue, and attention to society. These activities effectively improved the students' involvement and commitment to serve the community, and through such a service process, the students also developed an enhanced value of the inner self, a sense of responsibility, and an understanding of life care.

\section{Discussion}

CHS has become an important component of medical education worldwide and can be effectively integrated into the curriculum [48]. Unlike the CHS programs and research at medical colleges in other countries, those in mainland China are grossly inadequate. SUMC is the first medical college in China to introduce CHS programs as part of the medical education. It aims at improvement through exploration and constant learning from experience. CHS can be performed in different ways to reflect the multitude of community needs and adapt to the needs of students at different learning stages. All our participants spent more than $6 \mathrm{~h}$ per activity, which provided sufficient time for the students to
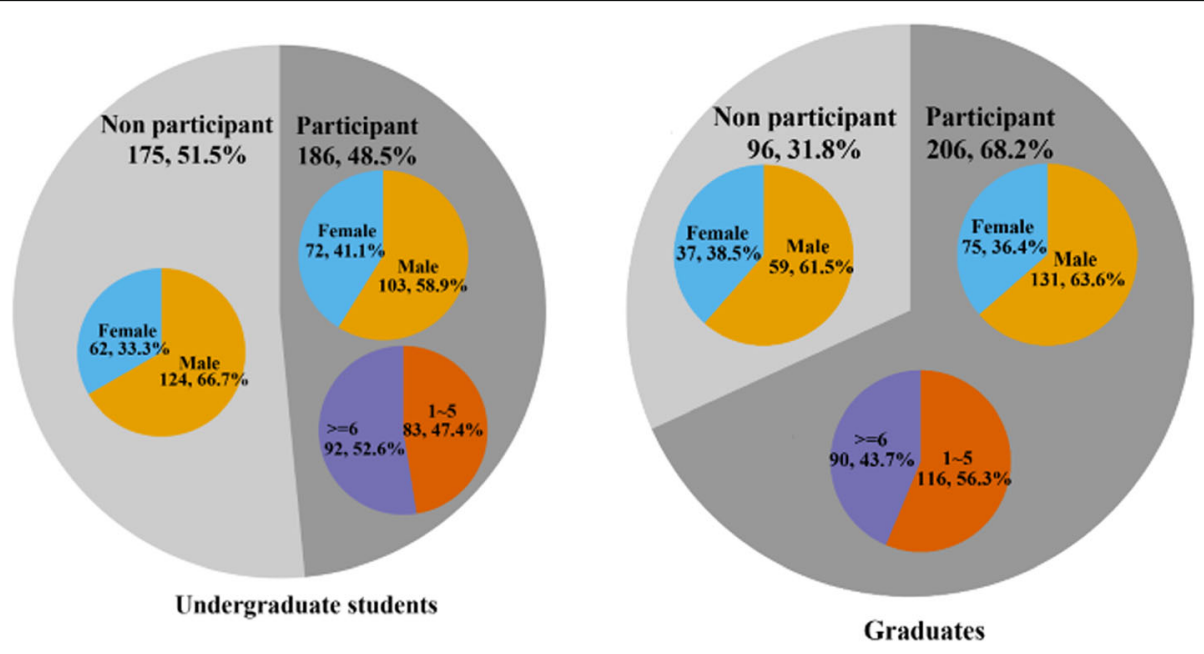

Fig. 2 Characteristics of the study population 
Table 3 Self-evaluation of medical ethical sensitivity development

\begin{tabular}{llll}
\hline Frequency 1-5 & & $\geq 6$ & $p$-value \\
\hline Graduates & $11(11.2 \%)$ & $36(40.0 \%)$ & $<\mathbf{0 . 0 0 1}$ \\
Great & $63(54.3 \%)$ & $42(46.7 \%)$ & 0.276 \\
Moderate & $40(34.5 \%)$ & $12(13.3 \%)$ & $\mathbf{0 . 0 0 1}$ \\
Little & 106 & 90 & \\
Total & $29(34.9 \%)$ & $31(33.7 \%)$ & 0.863 \\
Unergraduate Students & $31(33.7 \%)$ & 0.392 \\
Great & $23(27.7 \%)$ & $14(15.2 \%)$ & $\mathbf{0 . 0 4 3}$ \\
Moderate & $23(27.7 \%)$ & $16(17.4 \%)$ & \\
Little & $8(9.6 \%)$ & 92 & \\
Undecided & 83 & & \\
Total & & &
\end{tabular}

"Great/moderate/little" indicates the respondents' opinion that CHS had a great/moderate/little effect on their ethical sensitivity development.

"Undecided" indicates that the respondents could not make a choice

*Significant level: $p \leq 0.05$

understand the living plight and real needs of the poor people, as opposed to a one-to-one meeting in the clinic.

The main participants were third- and fourth-year medical students, who were in the transition stage between basic medical science and clinical training [49]. The comments of the participants were very positive and consistent, especially regarding the development in their sensitivity toward ethical cognition. Most of the participants believed that CHS had a great or moderate impact on their ethical cognition development. This

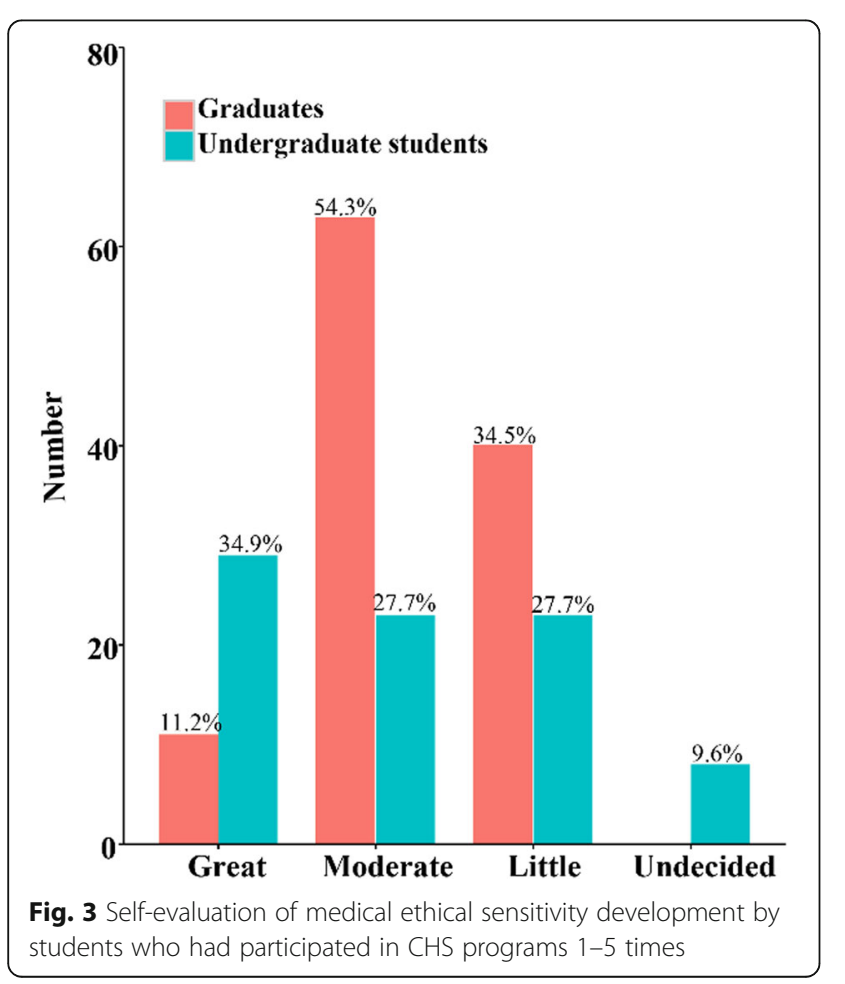

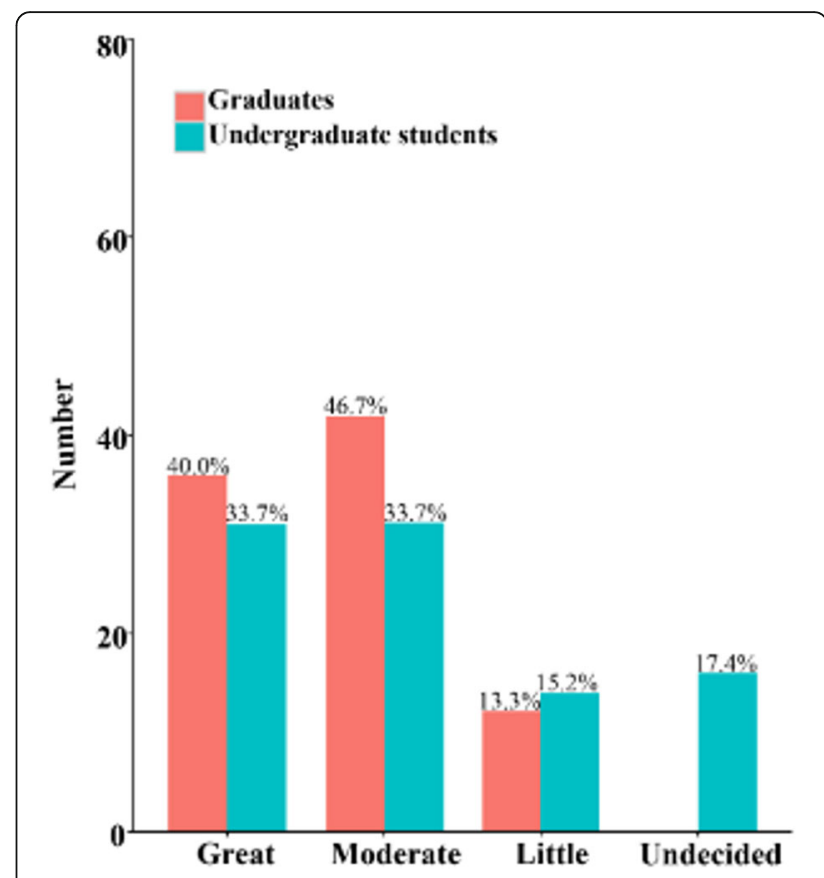

Fig. 4 Self-evaluation of medical ethical sensitivity development by students who had participated in CHS programs more than 6 times

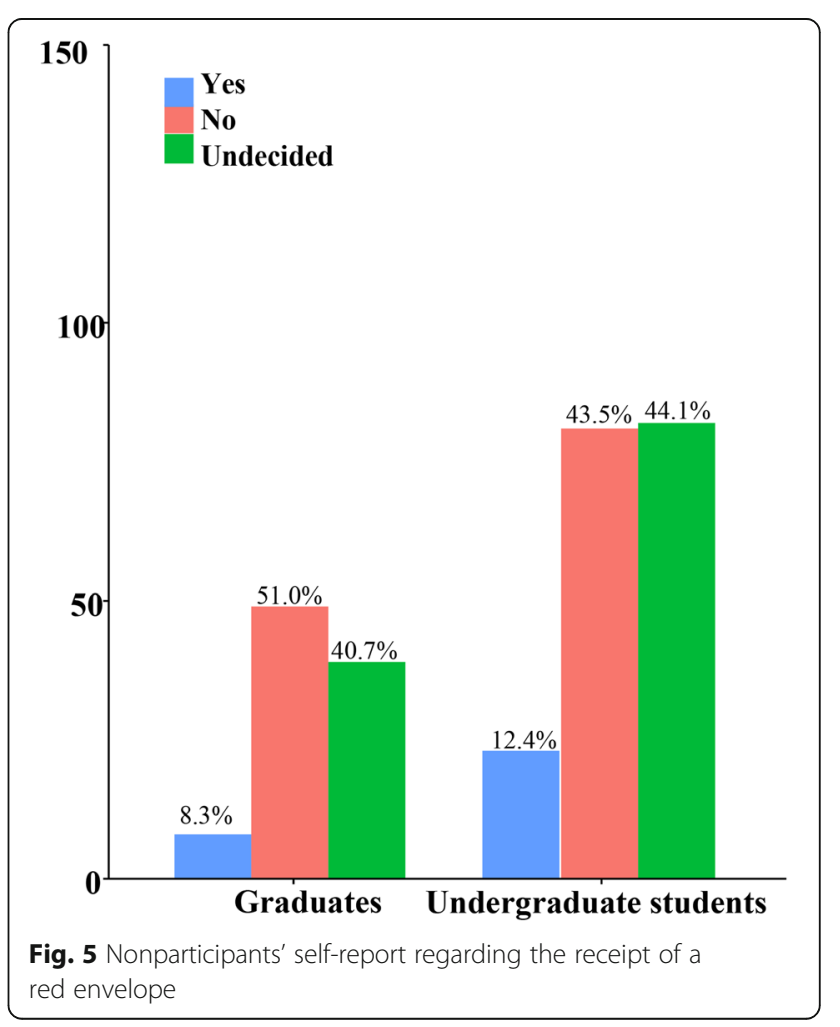




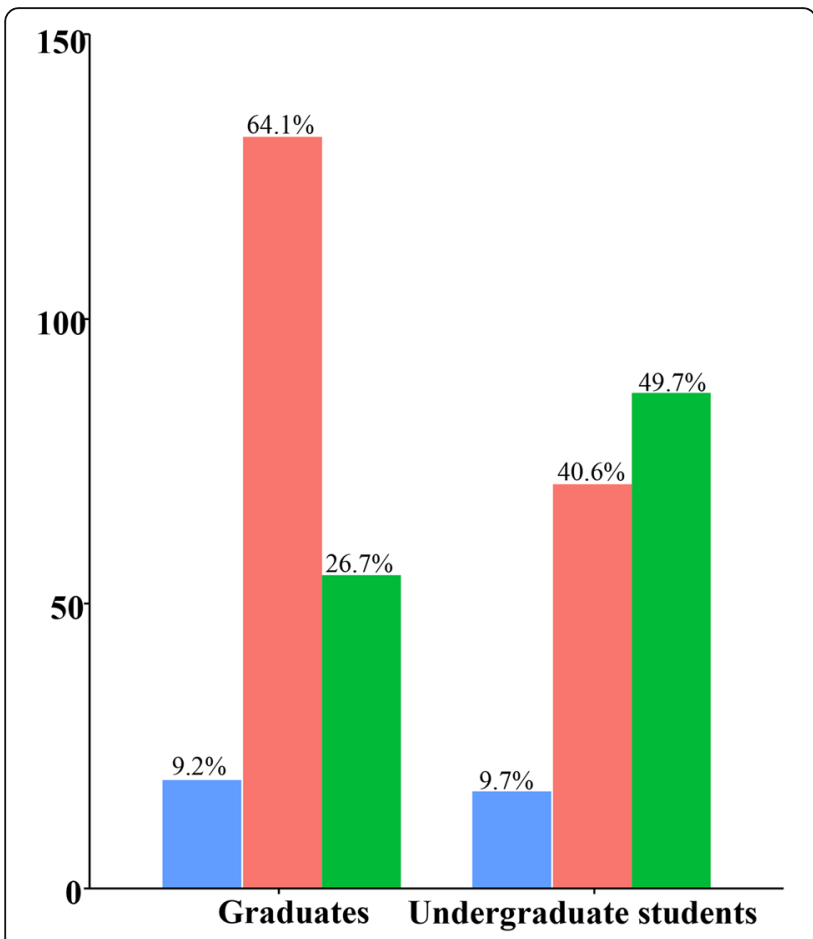

Fig. 6 Participants' self-report regarding the receipt of a red envelope

indicates that CHS programs are acceptable to students in mainland China.

In China, the exchange of red envelopes has been a widespread phenomenon in medical circles [50]. This is a method of rewarding physicians for special care and of expressing appreciation. The red envelope was originally developed as a manner of expressing courtesy and respect in East Asian countries, but physicians began to abuse the practice, demanding a red envelope from patients or their families. The red envelope even became a

Table 4 Node level and material information

\begin{tabular}{|c|c|c|c|}
\hline \multicolumn{2}{|c|}{ Tree node and child node } & \multirow{2}{*}{$\begin{array}{l}\text { Material } \\
\text { source }^{a}\end{array}$} & \multirow{2}{*}{$\begin{array}{l}\begin{array}{l}\text { Reference } \\
\text { point }^{b}\end{array} \\
18\end{array}$} \\
\hline \multirow[t]{7}{*}{ Cognition } & Motivate us to study hard. & & \\
\hline & $\begin{array}{l}\text { Better understanding and } \\
\text { compassion for patients. }\end{array}$ & 19 & 20 \\
\hline & $\begin{array}{l}\text { Aware of there are a lot of people } \\
\text { suffering with chronic diseases. }\end{array}$ & 17 & 23 \\
\hline & Helping others is meaningful. & 12 & 13 \\
\hline & $\begin{array}{l}\text { Thought preparation for being a } \\
\text { doctor. }\end{array}$ & 7 & 10 \\
\hline & $\begin{array}{l}\text { To understand the status quo of rural } \\
\text { areas. }\end{array}$ & 7 & 7 \\
\hline & $\begin{array}{l}\text { Aware of the importance of } \\
\text { communication. }\end{array}$ & 2 & 2 \\
\hline
\end{tabular}

${ }^{a}$ The number of interviews with the node

${ }^{\mathrm{b}}$ The source of the node in the interview material
Table 5 Self-report regarding the receipt of a red envelope

\begin{tabular}{llll}
\hline \multicolumn{2}{c}{ No participant } & Participant & $p$ \\
\hline \multicolumn{2}{l}{ Will you accept patients 'red envelope'? } & & \\
\multicolumn{2}{l}{ Undergraduate Students } \\
Yes & $23(12.4 \%)$ & $17(9.7 \%)$ & 0.423 \\
No & $81(43.5 \%)$ & $71(40.6 \%)$ & 0.567 \\
Undecided & $82(44.1 \%)$ & $87(49.7 \%)$ & 0.284 \\
Graduates & & & \\
Yes & $8(8.3 \%)$ & $19(9.2 \%)$ & 0.801 \\
No & $49(51 \%)$ & $132(64.1 \%)$ & $\mathbf{0 . 0 3 1}$ \\
Undecided & $39(40.7 \%)$ & $55(26.7 \%)$ & 0.015 \\
\hline
\end{tabular}

"Participant" indicates those who had participated in the CHS programs; "nonparticipant" indicates those who had not participated in the CHS programs

*Significant level: $p \leq 0.05$

major source of income for physicians, markedly hampering the doctor-patient relationship. Demanding a red envelope is an unethical practice and is banned in China, but it still occurs widely in private. A study revealed that $54.4 \%$ of patients $[51,52]$ had given a red envelope to doctors to be favored for hospitalization or surgery. Therefore, we chose the red envelope as an index for the self-report of ethical behavior. Although the ethical behavior self-report regarding the red envelope showed no significant differences $(p=.567)$ among the students, significant differences were observed $(p=.031)$ among the graduates. The development of ethical sensitivity and moral maturity is a gradual process and requires frequent training and practice. The CHS activities of the medical students are especially effective in identifying community patients' unmet needs [53].

Medical ethics education is an important part of medical education, and it helps students to establish the proper values, outlook on life, and world view, which are related to medical ethical cognition and behavior [54]. Leading and promoting medical students to develop appropriate medical ethics constitute a crucial purpose of medical education and a key marker for evaluating the effectiveness of medical education. CHS exerts a subtle influence on medical students' ethical cognition, and many participants believed that CHS had a great impact on their ethical cognition development.

The major contributions of this study are as follows.

First, we used a self-report method to verify the effectiveness of CHS for intervening in the potential regression of morality in junior medical students influenced by Chinese culture.

Second, our study verified the self-regulation theory and the effectiveness of community medical service in moral compensation. Our results suggested that through CHS activities, the students' moral awareness was raised, which prevented them from regressing on the morality 
scale. In this article, this effect is termed the "prevention focus" of CHS.

Third, through the evaluation of community medical service activities, we preliminarily explain the paradox between medical students' morality education and the regression of morality among them. According to compensation theory, unethical behavior damages the moral self-image of physicians. To restore this image, the physicians then perform some positive action as compensation. However, in reality, the morality regression phenomenon is still observed, implying that in Chinese culture, the ethical regression in a small percentage of physicians will increase in severity.

Our findings revealed that to avoid a long-term regression in medical students' morality, strengthening their understanding of immoral behavior is essential. People with morality problems may rationalize their behavior; specifically, they do not consider their behavior immoral. In our study, the community medical service activities had a moral compensation effect. The students could first identify which behavior is moral and then could continue compensating for it.

Finally, this study supports the view that the community medical service activities had a prevention focus effect, which can deter unethical behaviors among medical students. Service activities can also activate the students' cognition toward social medical activities and avoid a morality decline in their long-term career, which prevents immoral cognition from developing into real unethical behavior.

Several limitations of this study should be noted. The impact on cognition is a long-term process and should be monitored and evaluated constantly. We evaluated only the differences between participants and nonparticipants in medical ethics cognition and behavior selfreports through a single survey and ignored the relationship between students' volunteer experiences and their medical school academic performance, clinical skills, and residency performance. All participation was voluntary, and those who participated were more likely to report a positive attitude toward extracurricular activities. Dynamic research requires constant follow-up. In addition, other factors potentially influencing the community students' cognition and the community patients' responses and satisfaction might exist [54]. Ultimately, CHS programs are at an immature stage and have not sufficiently been integrated into the medical education curriculum.

\section{Conclusions}

In summary, CHS in mainland China may play a crucial role in medical education. The inclusion of CHS in medical education is welcomed by medical students, and our findings are a reference for promoting CHS in other medical schools in mainland China. We hope that our success in integrating this concept into medical education serves as a catalyst for the wider application of this concept by other medical universities in mainland China.

\section{Practice points}

- The inclusion of CHS in medical education is welcomed by Chinese medical students.

- CHS has a prevention focus, which can deter unethical behaviors among medical students.

- CHS has a clear effect on ethical cognition, which should be promoted.

\section{Abbreviations}

CHS: Community health service; SCT: Social cognitive theory; SPSS: The Statistical Package for Social Sciences (IBM SPSS Statistics 19.0);

SUMC: Shantou University Medical College

\section{Acknowledgments}

The preparation for this paper is supported by Shantou University Medical College. Li Ka Shing Foundation provided support for the community medical service programs. All authors express appreciations to the support of sample selected doctors, graducate and unedergraduate students.

\section{Authors' contributions}

GF undertook the design of the study, full access to all of the data in the study and takes responsibility for the integrity of the data and the accuracy of the data analysis, undertook literature reviews, interpreted the results, and wrote the manuscript. $L L$ and $M C$ were in charge of the conception and design of study. ZL and YL performed the data collection. GF ultimately modified the manuscript. All authors read and approved the final manuscript.

\section{Funding}

Key subjects of the Ministry of education of the National Educational Science Planning Project (grant number: DIA150305).

\section{Availability of data and materials}

The datasets used and analyzed during the current study are available from the corresponding author on reasonable request.

\section{Ethics approval and consent to participate}

All subjects provided verbal informed consent to inclusion before they participated in the study, and the protocol was approved by the Ethics Committee of the Medical College of Shantou University (Code: SUMC-2016-39).

\section{Consent for publication}

Not applicable.

\section{Competing interests}

The authors declare that they have no competing interests.

\section{Author details}

${ }^{1}$ Shantou University Medical College, 22 Xin Ling Road, Shantou 515041, China. ${ }^{2}$ The First Affiliated Hospital of Shantou University Medical College, 57 Chang Ping Road, Shantou 515041, China. 3Shenzhen Children's Hospital, 7019 Yitian Road, Shenzhen 518172, China.

Received: 31 January 2018 Accepted: 6 June 2019 Published online: 01 July 2019

\section{References}

1. Blumenthal D, Hsiao W. Lessons from the East--China's rapidly evolving health care system. N Engl J Med. 2015;372(14):1281-5.

2. Elyer J. Reflection: linking service and learning-linking students and communities. J Soc Issues. 2002;58(3):517-34.

3. Bhayat A, Vergotine $G$, Yengopal V, Rudolph MJ. The impact of service-learning on two groups of south African dental students. J Dent Educ. 2011;75(11):1482-8. 
4. Abedini NC, Gruppen LD, Kolars JC, Kumagai AK. Understanding the effects of short-term international service-learning trips on medical students. Acad Med. 2012;87(6):820-8.

5. Main EE, Garrett-Wright D, Kerby M. Nursing student voices: reflections on an international community health service experience. Ky Nurse. 2013;61(1):10-1.

6. Yang G, Kong L, Zhao W, Wan X, Zhai Y, Chen LC, Koplan JP. Emergence of chronic non-communicable diseases in China. Lancet. 2008;372(9650):1697-705.

7. Li Y, Zhang M, Jiang Y, Wu F. Co-variations and clustering of chronic disease behavioral risk factors in China: China chronic disease and risk factor surveillance, 2007. PLoS One. 2012;7(3):e33881.

8. Yang Y, Yang D. Community health service centers in China, not always trusted by the populations they serve? China Econ Rev. 2009:20(4):620-4.

9. Geiger HJ. Community-oriented primary care: a path to community development. Am J Public Health. 2002:92:1713-6.

10. Carey GE, Braunack-Mayer AJ. Exploring the effects of government funding on communitybased organizations: 'top-down' or 'bottom-up' approaches to health promotion? Glob Health Promot. 2009;16:45-52.

11. Bandura A. Social foundations of thought and action: a social cognitive theory. Englewood Cliffs, NJ: Prentice-Hall; 1986.

12. Bandura A. Social learning theory. Englewood Cliffs, NJ: Prentice Hall; 1977.

13. Roberts C, Daly M, Held F, Lyle D. Social learning in a longitudinal integrated clinical placement. Adv Health Sci Educ. 2016:1-19. https://doi. org/10.1007/s10459-016-9740-3

14. Williams L, Labonte R. Changing health determinants through community action: power, participation and policy. Promot Educ. 2003;10:65-71.

15. Bringle RG, Phillips MA, Hudson M. The measure of community medical service: research scales to assess student experiences. Washington D.C: American Psychological Association; 2004.

16. Newman P, Peile E. Valuing learner's experience and supporting further growth: educational models to help experienced adult learners in medicine. Br Med J. 2002;325:200-2.

17. Porter-Williamson K, von Gunten CF, Garman K, Herbst L, Bluestein HG, Evans W. Improving knowledge in palliative medicine with a required hospice rotation for third-year medical students. Acad Med. 2004;79(8):777-82.

18. Ratanawongsa N, Teherani A, Hauer KE. Third-year medical students' experiences with dying patients during the internal medicine clerkship: a qualitative study of the informal curriculum. Acad Med. 2005;80(7):641-7.

19. Wear D. "Face-to-face with it": medical students' narratives about their endof-life education. Acad Med. 2002;77(4):271-7.

20. Long JA, Lee RS, Federico S, Battaglia C, Wong S, Earnest M. Developing leadership and advocacy skills in medical students through service learning. J Public Health Manag Pract. 2011;17(4):369-72.

21. Jefferson AL, Cantwell NG, Byerly LK, Morhardt D. Medical student education program in Alzheimer's disease: the PAIRS program. BMC Med Educ. 2012;12:80.

22. Magnani JW, Minor MA, Aldrich JM. Care at the end of life: a novel curriculum module implemented by medical students. Acad Med. 2002; 77(4):292-8.

23. Ventegodt S, Morad M, Press J, Merrick J, Shek DT. Clinical holistic medicine: holistic adolescent medicine. Sci World J. 2004;4:551-61.

24. Xiao YY, Li T, Xiao L, Wang SW, Wang SQ, Wang HX, Wang BB, Gao YL. The Chinese version of instrument of professional attitude for student nurses (IPASN): assessment of reliability and validity. Nurse Educ Today. 2017;49:7983. https://doi.org/10.1016/j.nedt.2016.11.013.

25. Biwei Su, Almas Heshmati. 2013. Analysis of the determinants of income and income gap between urban and rural China. IZA Discussion Paper, No. 7162, Retrieved from http: // ssrn. com/abstract=2210822.

26. Israel BA, Checkoway B, Schulz A. Health education and community empowerment: conceptualizing and measuring perceptions of individual, organizational, and community control. Health Educ Q. 1994;21:149-70.

27. Deng D, Lin W, Law F. The study on evaluation and improvement of quality of life in patients with advanced cancer by China's hospice program. Am J Hosp Palliat Care. 2015;32(4):365-71.

28. Hearn J, Higginson IJ. Development and validation of a core outcome measure for palliative care: the palliative care outcome scale. Palliative care Core audit project advisory group. Qual Health Care. 1999;8:219-27.

29. Bassah N, Seymour J, Cox K. A modified systematic review of research evidence about education for pre-registration nurses in palliative care. BMC Palliat Care. 2014;13:56.
30. von Gunten CF, Mullan P, Nelesen RA, Soskins M, Savoia M, Buckholz G, Weissman DE. Development and evaluation of a palliative medicine curriculum for third-year medical students. J Palliat Med. 2012;15(11):1198-217.

31. Gugliucci MR. 48-hour hospice home immersion project: innovative medical education research. Innov Aging. 2017;1(Suppl 1):931.

32. Gomes B, Higginson IJ. Factors influencing death at home in terminally ill patients with cancer: systematic review. BMJ. 2006;332:515-21.

33. Giles D, Eyler J. The theoretical roots of service-learning in John Dewey: toward a theory of service-learning. Michigan J Serv Learn. 1994;1(1):77-85.

34. Butin DW. The limits of service-learning in higher education. Rev High Educ. 2006;29(4):473-98.

35. Packer $C$, Carnell R, Tomcho $P$, et al. Development of a four-day service-learning rotation for third-year medical students. Teach Learn Med. 2010;22:224-8.

36. Ferguson KJ, Wolter EM, Yarbrough DB, et al. Defining and describing medical learning communities: results of a National Survey. Acad Med. 2009;84(11):1549-56.

37. Coulehan J, Coulehan J. Today's professionalism: engaging the mind but not the heart. Acad Med. 2005;80(10):892-8.

38. Dharamsi S, Espinoza N, Cramer C, et al. Nurturing social responsibility through community service-learning: lessons learned from a pilot project. Med Teach. 2010;32(11):905-11.

39. O' Toole TP, Kathuria N, Mishra M, et al. Teaching professionalism within a community context: perspectives from a National Demonstration Project. Acad Med. 2005;80(4):339-43.

40. Rogers JC, Coutts L, et al. Do Students' Attitudes during Preclinical Years Predict Their Humanism as Clerkship Students? Acad Med. 2000;75(10 Suppl):74-7.

41. Griffith $\mathrm{CH}$, Wilson JF. The loss of student idealism in the 3rd-year clinical clerkships. Eval Health Prof. 2001;24(1):61-71.

42. Frankford DM, Patterson MA, Konrad TR. Transforming practice organizations to Foster lifelong learning and commitment to medical professionalism. Acad Med. 2000;75(7):708-17.

43. Tavakol S, Dennick R, Tavakol M. Medical students' understanding of empathy: a phenomenological study. Med Educ. 2012;46(3):306-16.

44. Hegazi I, Wilson I. Maintaining empathy in medical school: it is possible. Med Teach. 2013;35(12):1002-8.

45. Eyler J, Giles D. Where's the learning in service-learning? San Francisco: San Jossey-Bass; 1999.

46. Hsieh H, Shannon SE. Three approaches to qualitative content analysis. Qual Health Res. 2005;15(9):1277-88.

47. Ko KT, Yip PK, Liu SI, et al. Chinese version of the Zarit caregiver burden interview: a validation study. Am J Geriatr Psychiatry. 2008;16:513-8.

48. Trae $\mathrm{S}$, Zane $\mathbf{W}$. An overview of infusing community health service in medical education. Int J Med Educ. 2014;5:147-56.

49. Averill N, Sallee J, Elam C, et al. A first-year community-based service learning elective: design, implementation, and reflection. Teach Learn Med. 2007;19:47-54.

50. Yang HT, Li HY. The concept, Characteristies and legal attributes of 'red envelope'. Med Philos (Humanistic \& Social Medicine Edition). 2014;35(5):72-4 in Chinese.

51. Kong XJ, Du ZZ, Zhao MJ, Yang Y, Qin Y. Red envelope and doctor-patient trust:report of research on National Questionnaire Survey of 4000 inpatients in 10 cities (VII). Med Philos (Humanistic \& Social Medicine Edition). 2011; 32(5):34-7 in Chinese.

52. Fitz Gerald JD, Mangione CM, Boscardin J, et al. Impact of changes in Medicare home health care reimbursement on month-to-month home health utilization between 1996 and 2001 for a National Sample of patients undergoing orthopedic procedures. Med Care. 2006;44(9):870-8.

53. Mccullough MB, Petrakis BA, Gillespie C, et al. Knowing the patient: A qualitative study on care-taking and the clinical pharmacist-patient relationship[J]. Res Social Adm Pharm. 2015:S1551741115000777.

54. Tang L. The Chinese community patient's life satisfaction, assessment of community medical service, and trust in community health delivery system. Health Qual Life Outcomes. 2013;13:11-8.

\section{Publisher's Note}

Springer Nature remains neutral with regard to jurisdictional claims in published maps and institutional affiliations. 